\title{
ESTUDIO DE LA ISLA DE CALOR DE LA CIUDAD DE ALICANTE
}

\author{
Jorge Martínez Martínez \\ Máster en Climatología y Medios de Comunicación por la Universidad de Barcelona
}

\section{RESUMEN}

El fenómeno de isla de calor es tema actual y de gran trascendencia dentro de los estudios de clima urbano. A pesar de ello y de su tamaño poblacional, la ciudad de Alicante todavía no ha sido objeto de una investigación a fondo sobre dicha anomalía térmica. En este sentido, este artículo pretende de alguna manera iniciar estas investigaciones, dando lugar a unas primeras pautas de localización del máximo térmico y distribución de la isla de calor. Utilizando el método de los transectos se ha realizado la toma de temperaturas durante 10 días, dando lugar a la aparición de tres morfologías de isla de calor claramente definidas: la fuerte, débil y desplazada, que cuenta con un importante carácter geográfico. Así pues, podemos dar respuesta a una primera hipótesis sobre la existencia de este fenómeno en Alicante, puesto que de media, el centro de la isla marca $4,5^{\circ} \mathrm{C}$ más de temperatura sobre el punto frío o áreas urbanas menos cálidas.

Palabras clave: Clima urbano, isla de calor urbano, Alicante, transectos, configuración espacial, punto caliente.

\section{ABSTRACT}

\section{Study of the urban heat island in Alicante}

The phenomenon of the urban heat island is a current and importance issue in the urban climate studies. In spite of this and its population size, the city of Alicante has not been the subject of in depth research about the thermal anomaly as mentioned before. In this sense, this article expects to start these investigations in some way, giving rise to the first guidelines of location of the thermal maximum and distribution of the heat island. Using the method of the transects, the temperature measures have been carried out for 10 days, giving rise to the emergence of three morphologies of urban heat island clearly defined: the strong, the weak and the urban heat island in motion, which has an important geographic nature. Therefore, we can respond to the first hypothesis on the existence of this phenomenon in Alicante since on average, the center of the island marks $4.5^{\circ} \mathrm{C}$ warmer on the cold spot or urban areas less warm.

Key words: urban climate, urban heat island, Alicante, transects, spatial configuration, hot spot.

\section{INTRODUCCIÓN}

Fernando Chueca Goitia, en su célebre obra de 1968, "Breve historia del urbanismo", ya argumentaba que la ciudad podía estudiarse desde distintos ángulos: desde la historia, desde la geografía, desde la economía, desde la política, desde la sociología, etc. Así pues, el estudio de la ciudad o de lo urbano es una actividad que desde los orígenes mismos en que el ser humano decide organizarse en comunidades ha preocupado al mundo científico. Su relación con el espacio implica un doble proceso, de concentración de la población y de expansión espacial sobre un territorio al que va modificando drásticamente.

Y así es como podemos enlazar a unas ciencias que participan también en la ciudad, ciencias sobre las que dicho autor no se refiere, como son Climatología y Meteorología. Este hecho es de vital importancia ya que a los estudiosos de ambas disciplinas deben abordar el hecho de que la ciudad o urbe sea capaz de modificar las características atmosféricas del área geográfica concreta donde se insertan.

Así, la ciudad ha generado una serie de causas, que como veremos después dan lugar a lo que se ha denominado como isla de calor urbana, y en este sentido, el objetivo primordial de este trabajo de investigación científico es evidenciar la presencia de este fenómeno en la ciudad española de Alicante. Esto nos induce a desarrollar dos hipótesis sobre las que se va a asentar esta memoria:

Contacto: jorgemtnez86@gmail.com 
1. La existencia o no de una isla de calor en la ciudad de Alicante y dar explicación a su intensidad y distribución geográfica.

2. Comprobar hasta qué punto las características espaciales y climáticas modifican este fenómeno dentro de nuestra área de estudio.

\section{ESTUDIO DEL CLIMA URBANO}

Este hecho concreto que hemos indicado, la variación de las características climáticas de un lugar por la ciudad, es un hecho de relevante trascendencia y actualidad, pero no obstante, su estudio no es novedoso. Debemos remontarnos a la Historia Antigua, con griegos y romanos, para observar los primeros estudios y preocupaciones sobre el clima urbano. Es a Hipócrates al que podríamos señalar como el primer científico preocupado por los cambios en la naturaleza introducidos por la ciudad, ya que en su obra denominada "De los aires, de las aguas y de los lugares" (S. V a. C.), ya relaciona el aire distinto de las ciudades. Séneca, más tarde, en el S. I se lamenta del aire pestilente de Roma, los cuales le provocaban hasta cambios de humor al abandonar la ciudad, introduciendo, por tanto, problemas ambientales en las urbes.

Siglos después, en la Edad Media, el hacinamiento y concentración de la población en ciudades amuralladas, sumado a la escasez de sistemas de recogida y reciclado de basuras, provoca efectos reconocidos, como los cambios producidos en la composición del aire. Londres, como ciudad importante, en esta época y en siglos posteriores, constituye el ejemplo más representativo de contaminación urbana, teniendo que recurrir a la prohibición de quema de carbón en la ciudad, a partir del siglo XII, y especialmente durante el siglo XVI.

Serán, por tanto, varios los autores que tomarán a la capital británica como objeto de estudio de sus obras. Autores tales como John Evelyn, con la obra "Fumifugium" (1661), donde se publica el considerado como primer tratado sobre contaminación atmosférica urbana u otros científico, como son Epp, que se centrará en Münich o Luke Howard, que realizará una propuesta científica para la clasificación de nubes. Otro estudioso de las islas de calor urbanas, es el francés Emilien Renou (1815-1902), el cual detecta el calentamiento anómalo del centro de París con respecto a la periferia. Estos estudios urbanos conocerán un impulso y mejora, gracias a las redes de observación meteorológica que a finales del siglo XIX, comenzarán a emplear datos meteorológicos para analizar las alteraciones climáticas urbanas.

No obstante, el empleo de datos de observatorios únicamente permite conocer las diferencias entre puntos muy concretos. Por tanto, supuso de vital importancia la novedosa metodología que introducirán varios estudiosos del clima urbano en el estudio del mismo, como por ejemplo, Schmidt en Viena y Peppler en Karlsruhe, que introducirán vehículos a motor con aparatos de medida para obtener numerosos datos mediante itinerarios por toda la ciudad, para calcular las diferencias de temperatura entre diversos puntos.

Después de la Segunda Guerra Mundial (1939-1945), el crecimiento económico, industrial y, sobre todo, territorial de prácticamente la mayoría de asentamiento urbanos, conlleva en que el estudio del clima urbano tenga repercusión en todos los rincones del planeta, tanto a mano de los científicos, geógrafos y físicos, en mayor medida, como a nivel de las instituciones. Así, la celebración de 1968 de un Symposium internacional sobre climas urbanos, promovido por la Organización Meteorológica Mundial, en 1970, impulsaron las investigaciones de climatología urbana de base local, centradas, sobre todo en el reconocimiento de la isla de calor de distintas ciudades. También debemos citar a Chandler, como impulsor del estudio de la isla de calor, tras la publicación de su obra en 1965.

Todos los continentes tienen ya ciudades con un estudio sobre su isla de calor, dándose sobre todo en Europa, Norteamérica y Japón, desde este punto de vista, los más importantes son (Tabla 1):

\begin{tabular}{|c|c|c|c|}
\hline CONTINENTE & CIUDAD & AUTOR & AÑO \\
\hline \multirow{7}{*}{ EUROPA } & París & Dettwiller & 1970 \\
\hline & Plymouth & Millward & 1976 \\
\hline & Glasgow & Hartley & 1977 \\
\hline & Roma & Colacino & 1978-1982 \\
\hline & Utrecht & Van Duk & 1980 \\
\hline & Cracovia & Morawska y Cebulak & 1981 \\
\hline & Viena & Bernhofer & 1984 \\
\hline \multirow{3}{*}{ NORTEAMÉRICA } & Nueva York & Bornstein & $1968-1972$ \\
\hline & Montreal & Oke, East y Maxwell & 1971 y 1975 \\
\hline & Ciudad de México & Jáuregui & 1973 \\
\hline \multirow{2}{*}{ SUDAMÉRICA } & Rio de Janeiro & Gallego & 1972 \\
\hline & Sao Paulo & Lombardo & 1985 \\
\hline \multirow{6}{*}{ ASIA } & \multirow{2}{*}{ Hiroshima } & Shitara & 1957 \\
\hline & & Fukuoka y Nobuyuki & 1980 \\
\hline & \multirow{3}{*}{ Tokyo } & Kayane & 1964 \\
\hline & & Sasakura & 1965 \\
\hline & & Nishizawa & 1979 \\
\hline & Delhi & Bahl y Padmanabharmurty & 1979 y 1982 \\
\hline ÁFRICA & Nairobi & Okoola & 1979 \\
\hline
\end{tabular}


Las peculiaridades climáticas y meteorológicas de las ciudades con respecto su entorno es algo que en nuestro país ya se anunciaba mediante las memorias de viajeros y cronistas allá por el siglo XVI. No obstante, no será hasta el siglo XIX en que se extraigan consideraciones de tipo climático, gracias en gran medida a las mediciones de aparatos meteorológicos instalados en algunas ciudades, la primera de ellas, Barcelona en Enero de 1780.

En este sentido, los estudios e investigaciones sobre el clima urbano e isla de calor en España son muy actuales, ya que hasta la década de los años 80. Se comienza a utilizar el método de los recorridos con medidas directas para detectar la isla de calor en las ciudades españolas, actividad que corresponderá en mayor medida al trabajo y esfuerzo de los geógrafos. Así, Madrid será la ciudad en tratarse su isla de calor, con la colaboración conjunta del Consejo Superior de Investigaciones Científicas (CSIC) y la Universidad Autónoma de Madrid. Posteriormente los casos de Barcelona y otras ciudades catalanas, con los estudios de Carreras, Marín, Martín Vide, Moreno y Sabín, Valencia o Zaragoza serán tratados en este tipo de estudios. Estos trabajos también se han tratado incluso en los archipiélagos balear y canario, con los trabajos de Serra Pardo para Ibiza y Ruiz-Flaño y otros, para Las Palmas de Gran Canaria.

\section{EL FENÓMENO DE ISLA DE CALOR}

Este fenómeno conocido en inglés como Urban Heat Island (UHI), se define como anomalía térmica positiva en la parte central de las ciudades por contraste con la periferia. A menudo presenta forma concéntrica con las isotermas, abrazando el centro del área urbana, con preferencia en su mayor desarrollo en las horas nocturnas. En ciudades atravesadas por ríos pueden aparecer diferentes islas separadas por este hecho físico, el cual aparece como un canal frío.

Varios son los autores que han coincidido en enumerar las causas que contribuyen a generar este fenómeno:

1) Un mayor almacenamiento del calor durante el día en la ciudad, debido a las propiedades térmicas y caloríficas de los materiales de construcción urbanos y su devolución a la atmósfera durante la noche. Durante el día estos materiales se van calentando progresivamente, si bien de un modo más lento que el suelo de ámbitos rurales, desnudos o con vegetación, y durante la noche, se va enfriando, también muy lentamente, a diferencia de estos suelos. Este diferente enfriamiento explica la mayor intensidad nocturna del fenómeno.

2) La producción de calor antropogénico procedente de las diferentes actividades y procesos de combustión que se llevan a cabo en las áreas urbanas e industriales, como el transporte, la calefacción, alumbrado, etc.

3) La disminución de la evaporación, debido a la sustitución de la superficie natural originaria por un suelo asfaltado o pavimentado, de características diferentes y a la eficacia de los sistemas de drenaje urbanos. Esto propicia una rápida escorrentía de las aguas caídas con un episodio de lluvias, mientras que por otra parte, se impide el almacenamiento de esta en la superficie.

4) Una menor pérdida del calor sensible, debido a la reducción de la velocidad del viento por rozamiento de los flujos aéreos contra las diferentes formas y estructuras de la ciudad, que ofrecen una mayor resistencia a éste, actuando como parapetos.

5) Un aumento de la absorción de radiación solar, debido al efecto de captura que produce la singular geometría que presentan las calles y los edificios y que contribuye, a su vez, a un albedo relativamente bajo. La radiación solar incidente sufre múltiples reflexiones en las fachadas y en el suelo, quedando atrapada entre las calles, generando lo que se conoce como "cañón urbano" (Moreno García, 1993).

6) Reducción del factor de visión del cielo, incidiendo sobre la pérdida de calor durante la noche por irradiación, debido de nuevo a las características geométricas de calles y edificios.

7) La radiación de onda larga es emitida del suelo hacia la atmósfera y ante el obstáculo que representa la presencia partículas de contaminantes en la atmósfera urbana, es absorbida en parte de esta radiación por dicha capa, volviendo a remitir dicha capa hacia el suelo. Esto impide el paso de la radiación de onda larga hacia niveles atmosférico superiores y su pérdida al espacio.

Así pues, como podemos observar, las causas generadoras de este fenómeno no son lineales o continuas en el tiempo, y por lo tanto, podemos establecer el llamado "horario de la isla de calor", es decir, un factor temporal que dependiendo de las horas del día o estación del año, tendremos una intensidad mayor o menor de este hecho. Así, la isla de calor presenta un ritmo diario diferente, puesto que durante el día la intensidad es mínima, incluso puede que el ámbito urbano se mantenga a menor temperatura que el rural, ya que en este ámbito son menores los lugares situados a cubierto. Por el contrario, la anomalía positiva de temperatura es máxima en la ciudad a las horas nocturnas, generalmente después de la puesta del sol, 
ya que el campo sufre un enfriamiento más fuerte, fruto de la irradiación nocturna. Además podemos asegurar incluso, que en grandes áreas metropolitanas, la diferencia puede perdurar hasta cerca del amanecer y, por tanto, afectar a las temperaturas mínimas.

En cuanto al ritmo estacional, la isla de calor se intensifica en invierno con situaciones de calma anticiclónica y escasa nubosidad o bien con vientos débiles y cielos despejados o poco nubosos. No obstante, diversos estudios muestran que dependiendo de la ciudad estudiada, este fenómeno puede ser también intenso durante la época estival, como por ejemplo, el estudio llevado a cabo por Serra Pardo sobre la ciudad de Ibiza, la cual registra una isla de calor media durante invierno y verano similar, de $3^{\circ} \mathrm{C}$. $\mathrm{O}$ también la mayor intensidad durante el verano en una ciudad del Hemisferio Sur, como es Santiago de Chile, según las investigaciones de Pablo Sarricolea de 2012.

Así, la aparición de este fenómeno de isla calor sobre una ciudad conlleva una serie de características:

La intensidad de un episodio concreto de isla de calor, que se obtiene mediante la diferencia máxima de temperatura entre un punto urbano y otro rural o periférico. Hay que tener en cuenta que la medición de ambas temperaturas ha de darse sin una diferencia de tiempo considerable y que ambos puntos deben ser geográficamente comparables, sobre todo haciendo referencia a la altura sobre el nivel del mar.

Forma o configuración espacial que queda reflejada gráficamente mediante la disposición de las isotermas. Aquí participan factores urbanos, tales como la altura de los edificios, factor de visión del cielo, etc. siendo muy concreta en cada ciudad.

Localización del máximo térmico que hace referencia al punto geográfico donde se nos sitúa la intensidad máxima del municipio. Esta característica dependerá también de factores urbanos pero también de situaciones sinópticas concretas, como la situación sinóptica o dirección del viento dominante, que puede desplazar dicho centro.

\section{4. ÁREA DE ESTUDIO}

Por tanto, este estudio está centrada en el fenómeno de la isla de calor y particularmente la que se produce sobre la ciudad de Alicante. Esta ciudad, capital de la provincia homónima se encuentra en el Sureste de la Península Ibérica, a unos 38 20'43" latitud Norte y a $0^{\circ} 28^{\prime} 59^{\prime}$ longitud Oeste y a una altura de 0 metros sobre el nivel del mar.

En cuanto a aspectos demográficos, estamos haciendo referencia a una ciudad importante dentro del conjunto español, ya que en sus poco más de $201 \mathrm{~km}^{2}$, se concentran 334.678 habitantes (según datos oficiales del INE a 1 de Enero de 2012), por tanto una densidad de 1.662 habitantes por km², constituyendo la segunda población del País Valenciano y la $11^{\mathrm{a}}$ de España. Así pues estas peculiaridades demográficas pueden hacernos hablar, sin temor a equivocarnos de la proliferación de una isla de calor dentro de esta ciudad, anomalía que se verá condicionada por una serie de factores o características particulares de este ámbito que van a ser expuestos a continuación.

Imagen 1. Mapa del área de estudio.

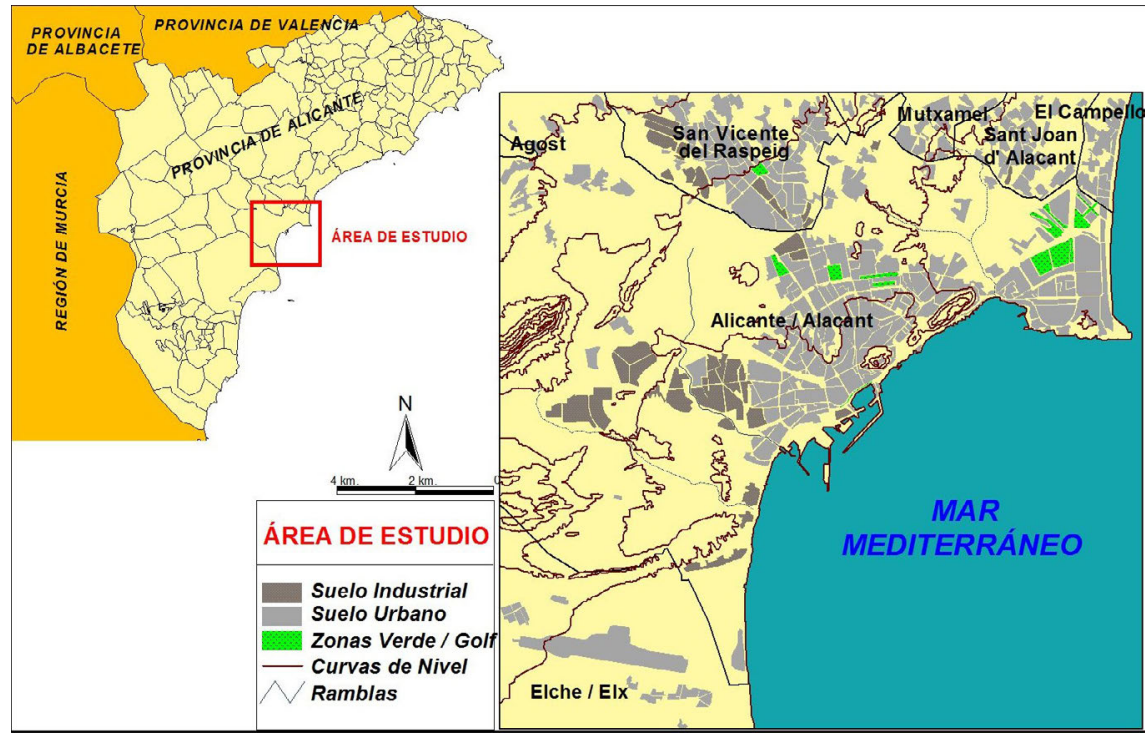

Fuente: Elaboración propia 


\subsection{Características físicas}

Tanto el término municipal de Alicante, como su población más directa, San Vicente del Raspeig, por la que también se ha trazado el estudio de este trabajo pertenecen a la comarca de L'Alacantí o Huerta de Alicante. Esta comarca presenta espacios abiertos que ocupan la mayor parte de la superficie, materiales sedimentarios blandos del Cretácico y Triásico con materiales Cuaternarios encostrados, elevándose sobre ellos, de modo aislado, enérgicos relieves montañosos, tales como la Serra de Fontcalent. Por otra lado, la cobertura mesozoica, constituida por estratos alternantes de margas, arcillas afectadas por la erosión constituyen cárcavas y barrancos, zonas de debilidad tectónica por las que discurren ramblas y ramblizos de escasa escorrentía.

El litoral debe su actual morfología a la neotectónica, causa de la reestructuración de bloques costeros que han modificado el antiguo perfil litoral: dovelas elevadas como el Cap de L' Horta, pero también Serra Grossa y Benacantil, las cuales superiores a los $130 \mathrm{mts}$. de altitud. También pueden advertirse zonas de material detrítico transportados por el sistema de drenaje y dinámica marítima, dando lugar así a playas y barras arena como Muchavista o el Postiguet y algunas veces de grava, playa de Campello o zona de Babel, profundamente integradas en el tejido urbano y modificadas por la acción turística.

Por otra parte, fruto de las escasas precipitaciones totales anuales de la región, la ciudad de Alicante no está atravesada por ningún curso fluvial importante, dándose una escorrentía intermitente a base de ramblas de funcionamiento espasmódico. Así nuestra área de estudio presenta una amplia ratícula de barrancos y ramblas destacando el barranco de Agua Amarga, con $70,8 \mathrm{~km}^{2}$ de cuenca vertiente y el Barranco de las Ovejas, de $226,6 \mathrm{~km}^{2}$. Al Noreste de la ciudad, aparece una antigua zona pantanosa, la playa de L'Albufereta, desecada en 1928 y sobre la que drena la cuenca de la Rambla d'Orgègia, que recoge la escorrentía de la pequeñas colinas que marcan el borde oriental de la Huerta, lomas de Garbinet y loma Redonda.

Las condiciones climáticas, temperaturas y precipitaciones nos enmarcan esta ciudad como un área inmersa plenamente en el dominio climático mediterráneo del Hemisferio Norte. Así pues, teniendo en cuenta las temperaturas registradas por la estación oficial de AEMET, situada en el barrio de Ciudad Jardín, nos muestra un temperatura media anual de $18^{\circ} \mathrm{C}$ y $334,7 \mathrm{~mm}$. Observamos unos inviernos suaves con unas mínimas medias que no bajan de los $10^{\circ} \mathrm{C}$, dándose en mínimo en Enero con $11,6^{\circ} \mathrm{C}$. Las máximas por su parte son cálidas, ya que superan las máximas superan los $30^{\circ} \mathrm{C}$ en los meses estivales, que sumado a la alta humedad que perdura durante esta época en Alicante, agrava la sensación de bochorno y por tanto, de temperatura sensible.

Las precipitaciones, como hemos comentado anteriormente se insertan dentro de unas características puramente mediterráneas del Sureste español, es decir, una estación seca, verano con sequías potentes y una estación lluviosa, otoño, sobretodo meses de Septiembre y Octubre con precipitaciones de fuerte intensidad horaria debido al caldeamiento excesivo del Mar Mediterráneo durante los meses anteriores.

Gráfico 1. Climograma perteneciente a la estación oficial de AEMET en Ciudad Jardín.

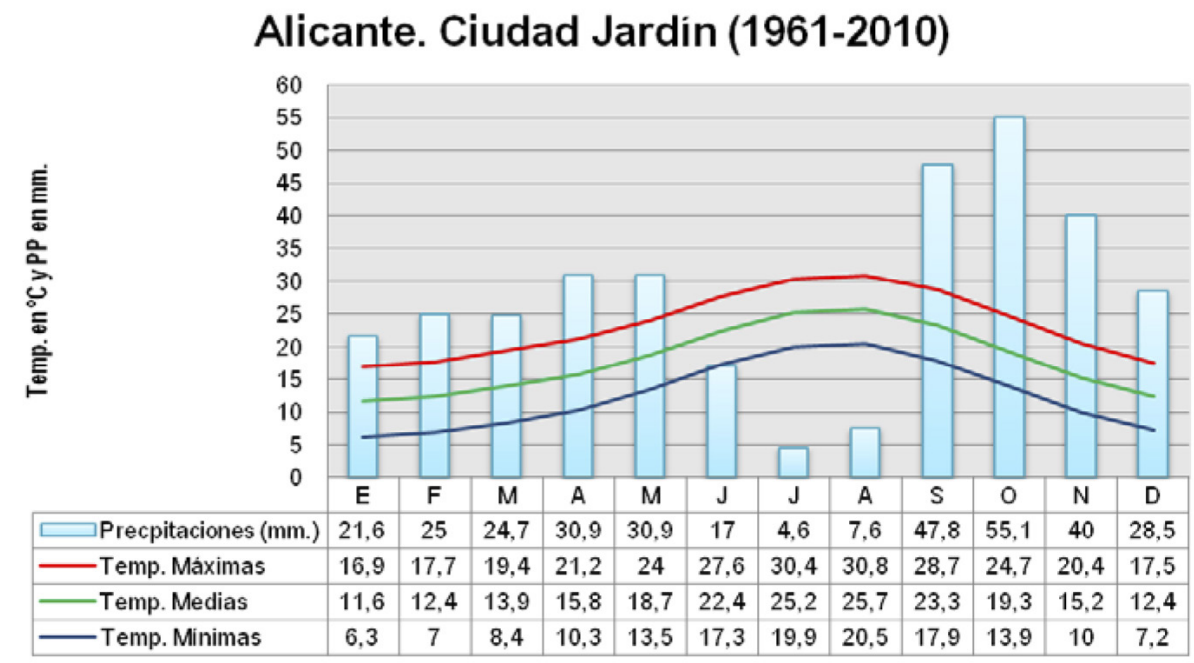

Fuente: AEMET 


\subsection{Características humanas}

Como se ha argumentado anteriormente, el fenómeno de isla de calor urbana depende directamente no sólo del número de habitantes que concentre una población, sino también de cómo se ha llevado a cabo ese proceso de urbanización y las distintas tipologías urbanas, edificatorias y materiales que se dan dentro de su seno. De este punto de vista, Alicante ha tenido un desarrollo característico, que condiciona la distribución de su isla de calor urbana.

Al iniciarse el siglo XX, Alicante ocupaba una extensión total de aproximadamente 178,1 has. y una población total de 51.874 habitantes. En la actualidad estos se elevan hasta las 2783 has. y 334.678 habitantes, es decir, un crecimiento del urbano del 1463,8\% y poblacional de 545,3\%, tan sólo en 112 años.

Gráfico 2. Evolución demográfica de Alicante.

\section{Alicante. Evolución demográfica (1858-2011)}

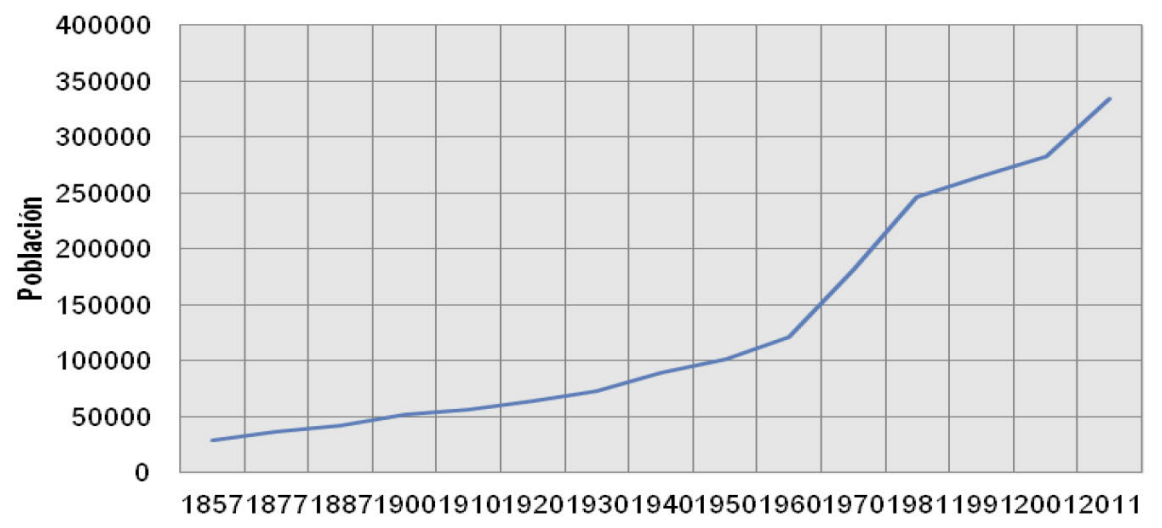

Fuente: INE.

Durante el primer tercio de siglo, el incremento poblacional fue sostenido hasta 1930, ya que por aquel entonces eran 73.071 habitantes, con unas pautas demográficas que ya hablaban de crecimiento vegetativo moderno, es decir, mortalidad y natalidad decrecientes al mismo tiempo. Se produjeron también en estos años numerosos cambios urbanísticos en la ciudad, con la aparición de barrios nuevos de forma espontánea, como Los Ángeles y otros con cierto pretensión urbanística como la Ciudad Jardín o el Barrio Obrero, al mismo tiempo, que se producen algunas transformaciones dentro de la urbe ya levantada, como la prolongación de la avenida Alfonso el Sabio o el desmonte de la Muntanyeta.

En la década de los 30, y pese a la Guerra Civil, la ciudad fue creciendo en efectivos, hasta llegar en 1937 holgadamente a los 100.000 habitantes debido a la emigración forzosa de guerra, al convertirse Alicante en tierra de asilo para quienes huían de las turbulencias bélicas. En las décadas siguientes, este crecimiento demográfico será pausado debido a las miserias de los primeros años de franquismo, aunque a nivel urbanístico hay que destacar el aprovechamiento de los bombardeos padecidos durante el conflicto bélico para introducir reformas urbanas e iniciar el equipamiento del litoral de la playa de San Juan y Muchavista. De esta forma la ciudad empezará a especializarse en el sector servicios.

Será a partir de la segunda mitad del siglo XX, concretamente la década de los 60, cuando Alicante conozca un crecimiento tanto demográfico como poblacional excesivo, fruto de la política desarrollista al uso de aquellos años. Ese crecimiento urbano procedía ya de la década anterior, pero ahora incrementa su velocidad además va imponiendo el uso del automóvil familiar. El aumento del tamaño de la ciudad y la especialización de diversas áreas, obligaban a un movimiento permanente de la población entre sus diversas calles, que se van convirtiendo en puras arterias de tráfico automovilístico, con su consiguiente congestión y contaminación.

Para paliar en alguna medida los graves problemas de tráfico de la ciudad, tan sólo en 1989 el parque de vehículos aumentó en 11000 unidades, se dio prioridad por la construcción de grandes vías de circunvalación como Gran Vía y la Vía Parque. Estas enormes avenidas, con amplios terrenos de zonas verdes, resuelven tanto problemas de conexión de la ciudad, como también el acceso de tráfico a distintos barrios 
periféricos. El colapso de la economía del mercado inmobiliario del ladrillo y la situación de parálisis económica mundial, también ha repercutido en el crecimiento tanto demográfico como poblacional de Alicante, resultando un periodo de crecimiento poblacional y urbano muy escaso (sólo ha crecido 2928 habitantes desde 2008).

Imagen 2. Desarrollo urbano de Alicante desde principios del siglo XX.
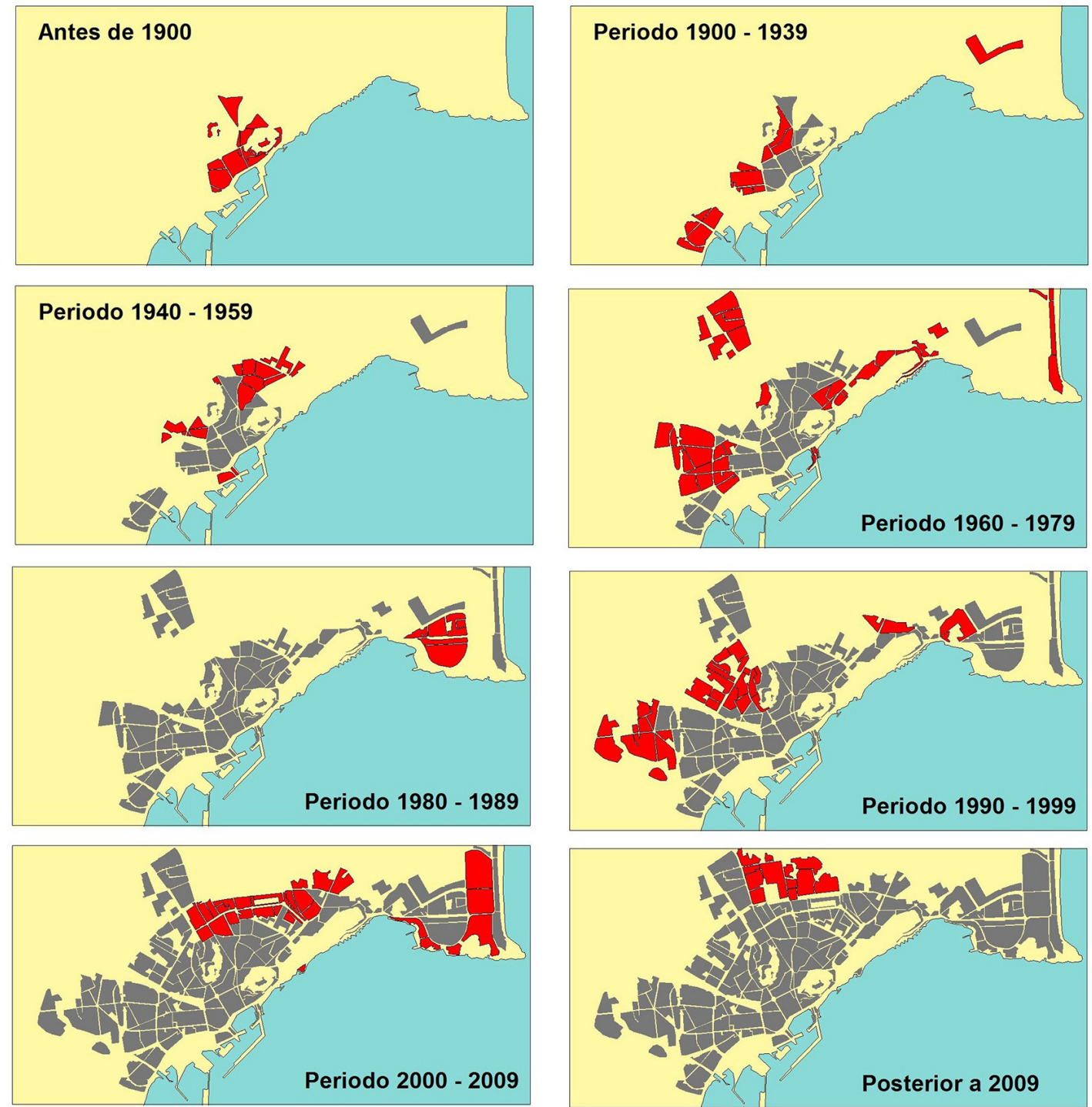

Fuente: Elaboración propia a partir de la Oficina Virtual del Catastro.

\section{METODOLOGÍA}

El estudio del fenómeno se ha llevado a cabo mediante la toma sistemática de medidas de temperatura sobre el propio terreno, a través de recorridos o transectos realizados con vehículos a motor por toda la ciudad. Éste ha sido el método utilizado para la realización de este trabajo, recogiendo el testigo de la metodología que, como hemos citado en el anterior apartado de estudio del clima urbano, introduce en 1930 Schmidt en la ciudad de Viena.

Esta técnica de estudio del fenómeno sobre el que estamos hablando es más preciso que las observaciones procedentes de los observatorios meteorológicos convencionales, ya que la finalidad principal de éstos es muy distinta en un orden de escala espacial y, por lo tanto, sus datos sólo pueden servir como referencia (Carreras et al.,1990) y teniendo en cuenta además, que en la ciudad de Alicante sólo contamos con dos observatorios oficiales, el de Ciudad Jardín y el ubicado en el aeropuerto de El Altet. En 
este sentido, se diseñaron cuatro transectos diferentes que cruzan tanto la capital alicantina como municipios y pedanías limítrofes para poder abarcar la intensidad del fenómeno en mayor espacio posible. Por tanto, en conjunto podemos hablar de un recorrido con una longitud total sensiblemente superior a los 44 kilómetros, entre los que se reparten los 55 puntos en los que se han ido captando las temperaturas, configurando una malla de puntos densa que se distribuyen cada 800 metros aproximadamente aunque en irregular distribución.

El instrumental utilizado con el que se realizaron las observaciones ha consistido en una estación termo-higrométrica digital Hanna, modelo HI-8064, con una sonda a una altura de 1,5 metros de altura, pinzada a la ventanilla del copiloto del automóvil. Dicho aparato presenta una baja inercia, por lo que, tal como indican las especificaciones de los mismos, se usó con el vehículo en marcha a una velocidad que siempre y cuando se ha podido ha sido en promedio de unos $40 \mathrm{~km} / \mathrm{h}$ por carreteras intraurbanas y unos $60 \mathrm{~km} / \mathrm{h}$ fuera de las mismas.

Las mediciones se llevaron en 10 fechas concretas, ya que por problemas de disponibilidad del autor se llevaron a cabo 9 durante el invierno de 2012-2013, en fechas 6, 7, 26, 27 y 28 de Diciembre del primer año, 3 y 4 de Enero y 6 y 7 de Febrero del segundo y una en Primavera, aunque el segundo día de dicha estación, es decir, el 22 de Marzo, por lo que tampoco se registraron valores de temperatura muy distintos. Por tanto, podemos hablar de que esta memoria ha contado con el tratamiento de 550 datos térmicos.

No obstante, se ha de tener en cuenta que los datos térmicos que se reflejan en esta memoria no son los datos registrados in situ con la estación termo-higrométrica, puesto que estos datos ha tenido que pasar por un filtro o como se ha querido llamar "corrección" para evitar el paso del tiempo transcurridos mientras que medían los mismos. Al realizar las tomas en horas de gran concentración de tráfico en algunos días y la longitud del recorrido, la duración de los transectos ha ido variando según el día de toma, pero en promedio esta actividad ha llevado 79 minutos diariamente, a los que hay que sumar el tiempo que transcurre en el desplazamiento del final de un transecto y hasta el inicio del siguiente, hablando por tanto, de 116 minutos totales de media. En la tabla 2 se refleja la hora de inicio y final desde la toma del primer punto hasta la toma de punto 55, teniendo en cuenta duración total de cada día y duración sólo durante los transectos:

\begin{tabular}{|cccccc|}
\hline DÍA & FECHA & $\begin{array}{c}\text { HORA } \\
\text { INICIO }\end{array}$ & $\begin{array}{c}\text { HORA } \\
\text { FINAL }\end{array}$ & $\begin{array}{c}\text { TOTAL } \\
\text { MINUTOS }\end{array}$ & $\begin{array}{c}\text { MINUTOS EN } \\
\text { TRANSECTOS }\end{array}$ \\
\hline 1. & $06 / 12 / 2012$ & $21: 23$ & $23: 30$ & 127 & 81 \\
\hline 2. & $07 / 12 / 2012$ & $21: 07$ & $23: 20$ & 133 & 86 \\
\hline 3. & $26 / 12 / 2012$ & $21: 06$ & $23: 10$ & 124 & 83 \\
\hline 4. & $27 / 12 / 2012$ & $20: 37$ & $22: 48$ & 131 & 82 \\
\hline 5. & $28 / 12 / 2012$ & $20: 32$ & $22: 39$ & 127 & 86 \\
\hline 6. & $03 / 01 / 2013$ & $20: 55$ & $22: 55$ & 120 & 76 \\
\hline 7. & $04 / 01 / 2013$ & $21: 01$ & $22: 39$ & 98 & 81 \\
\hline 8. & $06 / 02 / 2013$ & $21: 02$ & $22: 55$ & 113 & 64 \\
\hline 9. & $07 / 02 / 2013$ & $22: 51$ & $0: 23$ & 92 & 79 \\
\hline 10. & $22 / 03 / 2013$ & $22: 35$ & $0: 15$ & 100 & \\
\hline & MEDIA & & & 116 & \\
\hline
\end{tabular}

En este sentido, debemos tener en cuenta que la temperatura del aire, como variable meteorológica que es, no es lineal en el tiempo, sino que puede experimentar cambios débiles o bruscos con el paso de las horas y que por tanto, la temperatura que se daba al iniciar los transectos no era la misma que al finalizar. Por tanto, y como hemos anunciado arriba se procedió a una "corrección" de datos con el fin de evitar que la diferencia de temperatura entre sectores más cálidos y sectores más fríos sea lógica y no resultarnos una intensidad de la isla de calor que para nada sería lógica. Para realizar esta operación se ha utilizado la temperatura registrada durante las diversas horas en la estación oficial de AEMET que se sitúa en el aeropuerto de El Altet, por situarse a una altura de 43 metros sobre el nivel del mar, es decir, a una altura no muy alejada de la de los puntos de toma y, por tanto, sin tener que echar mano del gradiente de estado medio, es decir, de pérdida o ganancia de 0 ' $65^{\circ} \mathrm{C}$ cada 100 metros. El ejercicio se basa en calcular el número de décimas de diferencia entre una hora y otra y después dividirlas entre 60 minutos para ver cada cuantos minutos se ha pérdida o ganando una de estas décimas que serán sumadas o restadas a la temperatura registrada in situ de cada punto dentro de un determinado segmento de minutos. Por ejemplo, si se han perdido $0,6^{\circ} \mathrm{C}$ de una hora a otra, sumaremos una décima cada diez minutos, por lo que 
todas aquellos datos tomados entre la media hora y los 40 minutos, se les ha sumado tres décimas y así sucesivamente.

Después, una vez corregidos todos los datos, se ha procedido a extraer el mínimo diario y restarle la diferencia de este con el resto de datos, siendo esta diferencia la que se ha representado en los mapas de isotermas y por tanto, son estos datos con los que se pretende explicar la configuración del fenómeno de isla de calor en la ciudad de Alicante. El último paso final consiste en la elaboración de los mapas, que han sido realizados previamente con el programa Surfer 8, el cual permite realizar automáticamente mapas de isotermas, para posteriormente mejorarlos manualmente con el programa Arc View, con el que se ha perfilado el diseño final de la cartografía.

Así pues, y antes de entrar en materia con la distribución de la isla de calor en la ciudad de Alicante, es de vital importancia que tratemos el recorrido de cada uno de los transectos y la ubicación de los puntos de toma (imagen 3):

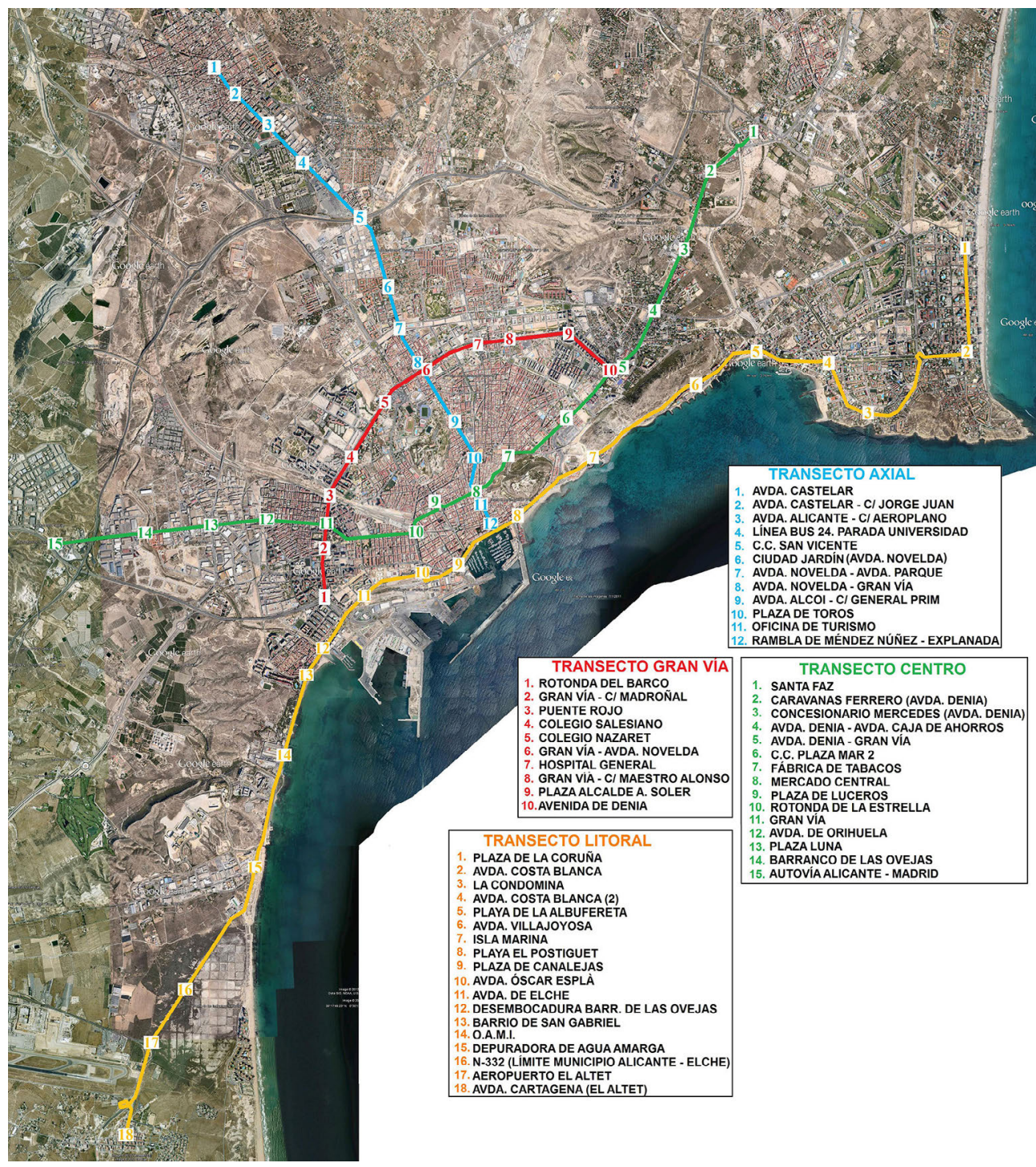

El orden de descripción de cada transecto viene determinado por el orden que se ha llevado a la hora de recorrerlos:

a) Transecto Axial

El primer transecto ha sido bautizado como axial, que con una dirección prácticamente en diagonal de Noroeste a Sureste, parte el área de estudio en dos mitades. El inicio se ubica en el centro de la población vecina de San Vicente del Raspeig hasta el final de la Rambla de Méndez Núñez en su contacto con la Explanada de España, en un total de 12 puntos de toma repartidos entre los 7100 metros aproxi- 
madamente que tiene el recorrido. La decisión de incluir al municipio de San Vicente del Raspeig en la investigación revista en que con una población de 55.100 habitantes (según INE a 1 de Enero de 2012), es una población suficientemente grande como para generar su propia isla de calor y que este trabajo de investigación pueda servir de apertura para el estudio de este campo.

Así pues, hablamos de un recorrido que comienza dentro de la principal avenida de San Vicente, la Avenida Castelar y que por lo tanto, hasta abandonar esta población, nos encontramos que una trama urbana densa de edificios de varias alturas. A la salida de la urbe sanvicentina nos topamos con las instalaciones de la Universidad de Alicante por su flanco Este en una vía amplia, Avenida de Alicante, que ocupa los terrenos del antiguo aeródromo militar de Rabasa y que empezó a funcionar en Octubre de 1979 y cuya terreno, si bien está pavimentado con adoquines tiene una extensión arbórea y herbácea reseñable, lo que conlleva la pérdida rápida del calor diurno durante las horas nocturnas. En esta avenida amplia comunica con la capital alicantina por el Norte, por barrios importantes como Los Ángeles o Barrio de Campoamor, donde se percibe una densidad constructiva y automovilística bastante densa, reduciéndose el factor de visión del cielo y sin apenas vegetación. El final de este transecto, como hemos indicado es establecido en la Rambla de Méndez Núñez. Actualmente, esta vía se presenta como una importante arteria comercial y lúdica, con una situación encajada entre edificios de gran altura y denso tráfico, pudiendo adelantar que será sin duda uno de los "puntos calientes" del fenómeno que tratamos.

\section{b) Transecto Centro}

El segundo transecto, el centro, comienza en el Plaza de Santa Faz, pedanía de 666 habitantes (Fuente: INE a 1 de Enero de 2011), en el que se ubica el monasterio del mismo nombre, lugar de culto y devoción del pueblo alicantino. Concluye en la salida a la Autovía Alicante-Madrid por la Carretera Ocaña, Polígono Industrial del Pla de la Vallonga, es decir, 11800 metros de longitud, para un total de 15 puntos de toma. Tiene una dirección general Noreste-Suroeste, conectando con las principales vías y avenidas del centro neurálgico de la ciudad alicantina.

Constituye un recorrido importante para el estudio del fenómeno, puesto que si bien empieza y acaba en zonas rurales o de escaso poblamiento urbano, la parte central del mismo se desarrollará en la principal vía de tráfico y comercial de todo Alicante, como es la unión Alfonso el Sabio - Avenida de la Estación. Es de destacar el paso por el principal curso fluvial, el Barranco de Las Ovejas, punto 14, pues como se ha estudiado, los ríos constituyen pasadizos por los que se desliza el aire frío o caliente, como se observará más adelante.

\section{c) Transecto Litoral}

El transecto litoral es el de mayor longitud, que recorre las vías paralelas a la costa, desde la Plaza de La Coruña en la Playa de San Juan hasta la pedanía de El Altet, ya en el término municipal de Elche. Así pues, el recorrido total de este tercer transecto tiene una dirección generalmente de Noreste a Suroeste, paralelo prácticamente al transecto centro, con 18 puntos de toma repartidos en una longitud total de 19300 metros. La intención de haber llegado al término municipal de Elche responde a las mismas pretensiones que con San Vicente del Raspeig, además el Aeropuerto de El Altet se inserta ya en este municipio en un área completamente despoblada por lo que supone un punto de interés para el trabajo.

Es un recorrido que presentan características similares con respecto al Transecto Centro, es decir, con un sector central que transcurre por vías neurálgicas de acceso y salida de la ciudad, como es la ronda litoral formada por las vías Avenidad Conde de Vallellano, la Avenida de Loring y Avenida de Elche, teniendo contacto por tanto con hitos emblemáticos de la ciudad como la Playa del Postiguet o los paseos de La Explanada-Canalejas. Los primeros cinco puntos de toma, no obstante, se insertan dentro del complejo turístico de urbanizaciones y residencias del Cabo del Cap de L'Horta, zona con calles de amplias avenidas y edificaciones de poca altura.

El tramo final del trayecto como hemos indicado se da en la N-332 que une los términos de Elche y Alicante, con un paisaje completamente despoblado, puesto que esta vía se inserta aquí sobre zonas lacustres y salubres, con vegetación halófila de hierbas bajas y arbustos en su mayoría y a una altitud sobre el nivel del mar que no superará los 3 metros. Esta vía nos está marcando ya el acceso el Aeropuerto de El Altet y la pedanía del mismo nombre.

d) Transecto Gran Vía

El último transecto que se ha recorrido cada día de toma es el Gran Vía, denominado así por que ocupa toda la extensión de esta vía, que como recordemos, se levantó a principios de la década de los 90, con el fin de convertirse en una enorme arteria de descongestión del tráfico intraurbano. Así pues, este 
trayecto tiene una longitud total de 6100 metros, tomándose registros en 10 puntos concretos. Las características de la vía, por tanto serán iguales durante todo el espacio de tiempo, siendo una vía de doble sentido en ambos lados, con unos márgenes ocupados por vegetación de origen antrópica, destacando sobre todo las arecáceas.

Al tener esta vía disposición semicircular, podemos hablar de una dirección general Sureste - Noroeste. Comenzando en la Rotonda del Barco, puerta de acceso a la ciudad por la Autovía de Madrid y finalizaremos el transecto en la intersección con Avenida de Denia, que anteriormente nos sirvió de toma de temperatura como punto 5 del transecto centro.

\section{ANÁLISIS DE LOS RESULTADOS. LA ISLA DE CALOR DE ALICANTE}

Como hemos enunciado anteriormente la isla de calor depende de una serie de factores intrínsecos para su mayor o menor intensidad dentro de una urbe, como por ejemplo se ha hablado del "horario" o de factores geográficos. En este sentido, las características meteorológicas o atmosféricas del día de toma de registros también nos condicionan las características, es decir, intensidad, distribución y localización del máximo, siendo viento y nubosidad los factores modificadores de estos conceptos. Es con días despejados o poco nubosos y vientos débiles o en calma, cuando se registra la mayor intensidad del fenómeno.

Por tanto, a la hora de hablar del fenómeno y su repercusión territorial en la ciudad de Alicante, debemos advertir las características meteorológicas de los días en los que se han registrado las temperaturas. Hay que advertir, en este sentido, que ante la falta de disponibilidad temporal del autor, podríamos hablar de que muchos días no han sido los más adecuados para el cálculo de la isla de calor alicantina, ya que debemos destacar el excepcional invierno ventoso de flujos de componente oeste, que ha padecido el litoral levantino español. No obstante, se intentará convertir estas desventajas en oportunidades para conseguir una mayor exposición de las características de la isla de calor alicantina.

Así pues, debemos establecer una clasificación clara de tipos de isla de calor dependiendo de las situaciones sinópticas concretas, clasificación que puede verse perfectamente ilustrada con la distribución de las isotermas. Se han detectado tres tipos claros de isla de calor en la ciudad de Alicante:

a) Isla de calor fuerte.

Este tipo de isla de calor responde a aquellos días en los que se ha registrado diferencia de temperatura entre la máxima registrada y la mínima superior a $5^{\circ} \mathrm{C}$. Estos días fueron el 26 y 28 de Diciembre de 2012, 4 de Enero y 22 de Marzo de 2013, percibiendo un máximo de intensidad que siempre se ha dado en la zona cercana al litoral, es decir, puerto y Avenida de Villajoyosa, correspondiendo a los puntos de Oficina de Turismo-Rambla de Méndez Núñez, Playa de El Postiguet y Avenida de Villajoyosa. La intensidad ha podido ocupar mayor o menor territorio pero siempre quedando restringida a este sector, donde debemos de destacar la presencia de la Rambla de Méndez Núñez en su contacto con la Explanada de España que ha sido capaz de registrar una media para este tipo de isla de calor de $5,4^{\circ} \mathrm{C}$. Descendiendo en una diferencia menor de temperatura pero aún así elevada, se percibe que en estos días, la concentración del calor se daba sobre todo en el área urbana de la capital alicantina, con temperaturas que en los casos más débiles de isla de calor superan aún así, ampliamente los $2^{\circ} \mathrm{C}$, caso del 26 de Diciembre y en otros casos de mayor intensidad como el 28 de Diciembre, prácticamente todo el centro urbano superaba los $4^{\circ} \mathrm{C}$ de diferencia sobre el mínimo.

En cuanto a la ubicación del mínimo en esta isla de calor debemos apuntar que ha ido variando, ya que si en los días de Diciembre el mínimo se registró en los últimos puntos del transecto litoral, en O.A.M.I. para el 26 y la N-332 para el 28, en los otros dos días el mínimo se registró al comienzo del transecto centro, siendo siempre en el punto 2, correspondiente a Caravanas Ferrero. En otros centros de población estudiadas como San Vicente del Raspeig, podemos hablar de una intensidad que decrece a medida que nos desplazamos desde el centro urbano, punto sobre todo de Calle Jorge Juan con Avenida de Castelar, hacia el Sur, donde es en el ámbito de la Universidad de Alicante, donde se registro menor fuerza del fenómeno.

La situación sinóptica que depara esta intensidad elevada de la isla de calor en Alicante responde a unas características atmosféricas excelentes para captar la mayor fuerza del fenómeno. Hablamos de una situación anticiclónica invernal, con una campo de altas presiones situado en la cercanías de la Península Ibérica, y que por tanto, comporta cielo despejado con algunas bandas de nubes altas y un viento débil que en ningún momento supere los $15-20 \mathrm{~km} / \mathrm{h}$. 
Tabla 3. En las imágenes superiores corresponden al geopotencial a $850 \mathrm{hPa}$ del 4 de Enero de 2013 a las 18:00 UTC y el campo de isotacas del mismo día y hora.
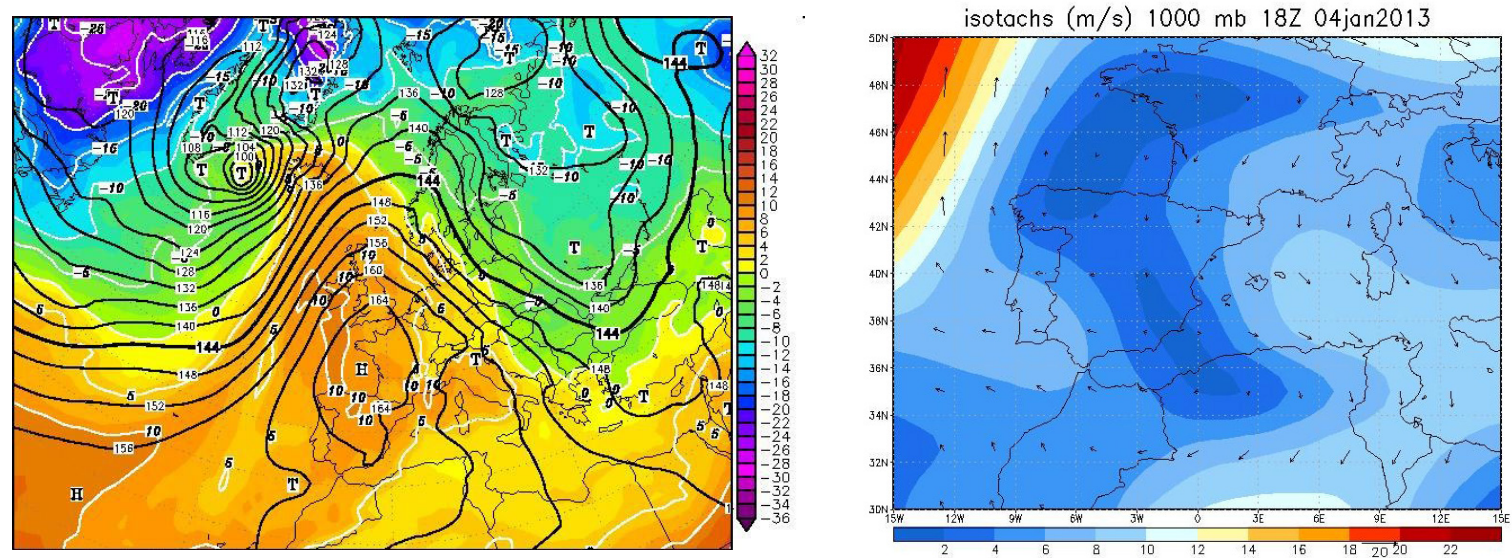

Fuente: Geopotencial extraído de www.wetter3.de y campo de isotacas de los plots disponibles de http://gama.am.ub.es/castellano/ castellano.htm

Estas situaciones sinópticas deparó la configuración de la siguiente isla de calor:

Imagen 4. Configuración de la isla de calor del 4 de Enero de 2012. Se observa que el mínimo se desplaza hacia el Norte del área de estudio, siendo importante esa corriente de Norte, es decir, aire más frío que se canaliza por la Rambla d'Orgègia.

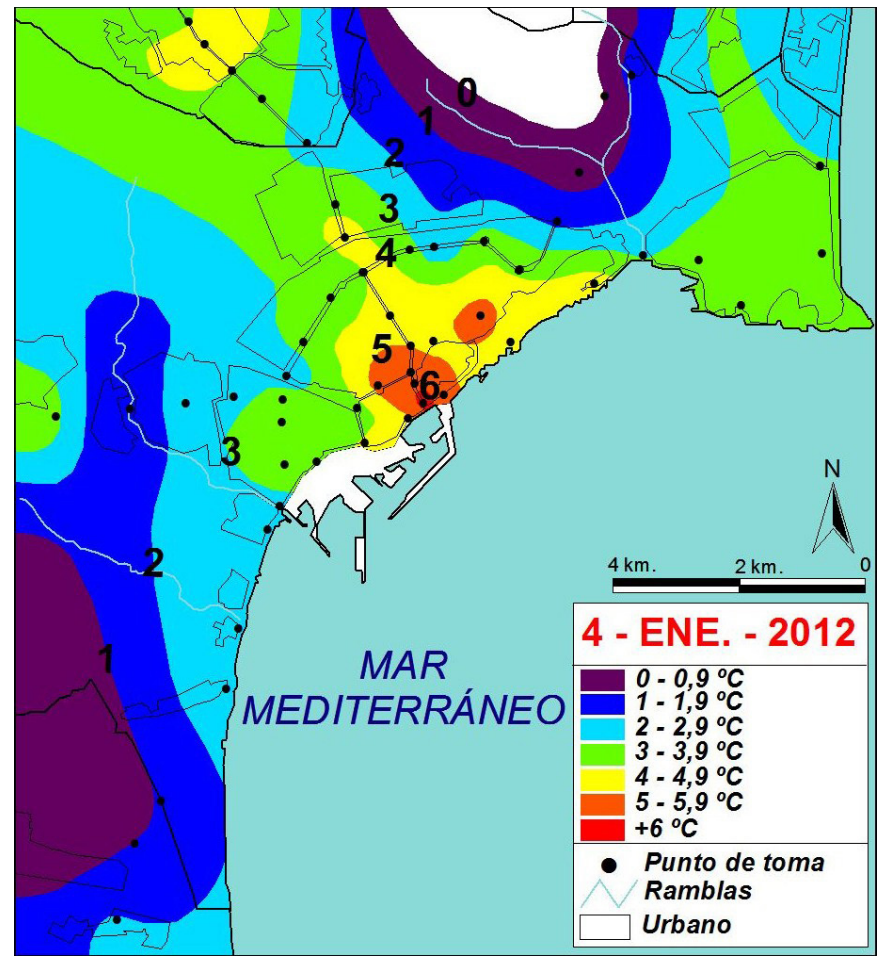

b) Isla de calor débil o sin isla

Se ha optado por denominar isla de calor débil o sin fenómeno reseñable cuando la diferencia entre el máximo y el mínimo registrado es igual o inferior a $4^{\circ} \mathrm{C}$. Esto no significa que $4^{\circ} \mathrm{C}$ sean escasos a la hora de hablar de una isla de calor débil, pero este registro se detectó tan sólo un día y además en una zona que queda fuera de los lugares más cálidos, por lo que podemos llegar a pensar que este registro se obtuvo por una situación atmosférica concreta. Este punto corresponde al inicio de la avenida Óscar Esplà, punto 10 del transecto litoral.

Esta distribución se ha presentando como fruto de una situación atmosférica de cielo parcialmente nuboso, con bandas de nubes altas y medias que durante gran parte del día ha estado tapando el cielo, 
impidiendo que los materiales de construcción urbanos absorbiesen todo el calor latente que con cielo completamente despejado sucede. Esto sucedió los días 6 y 7 de Diciembre de 2012, donde una borrasca situada en el frente a las costas de Galicia que entre la madrugada de ambos días se desplazo hacia el Golfo de Cádiz, trajo bastante nubosidad asociada de tipo medio y alto, tapando toda la mitad Sur de la península. El día 7, a la hora de la toma de los registros térmicos, la nubosidad prácticamente había desparecido, si acaso algunos cirros o cirrocúmulos, pero lo que difuminó realmente el fenómeno de isla de calor en la ciudad fue el viento que se sopló de componente Oeste y Suroeste con una racha máxima que llegó en las primeras horas de la noche a los 35-40 km/h.

Tabla 4. Reanálisis de la situación sinóptica en superficie el 6 de Diciembre a las 18:00 UTC e imagen del canal infrarrojo del satélite EUMETSAT el 7 de Diciembre a las 00:00 UTC.
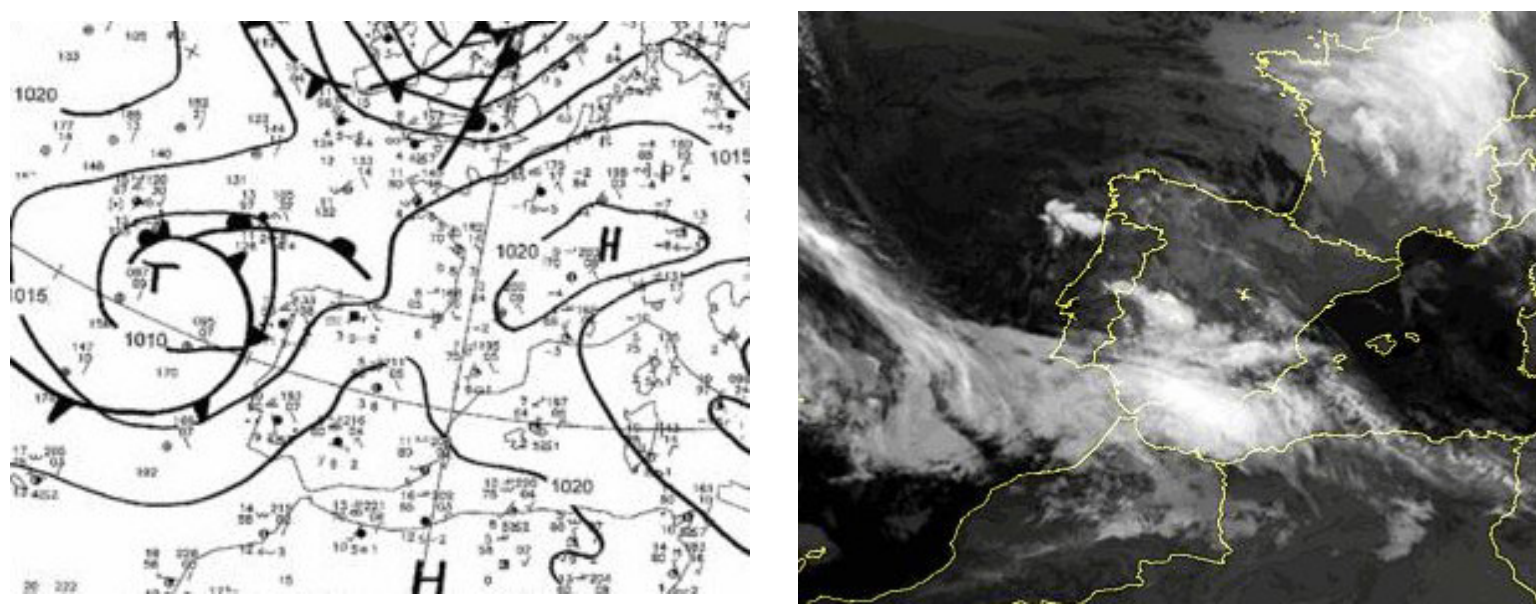

Fuentes respectivas: www.wetter3.de y www.sat24.com

Situación que dibujó el día 6 de Diciembre la siguiente isla de calor:

Imagen 5. Configuración de la isla de calor del día 6 de Diciembre de 2012. Al día siguiente, la disposición fue la misma, pero con una intensidad de $3^{\circ} \mathrm{C}$ en la zona de la Rambla de Méndez Núñez puesto que la nubosidad fue menor este día y sí hubo una radiación mayor que el día anterior.

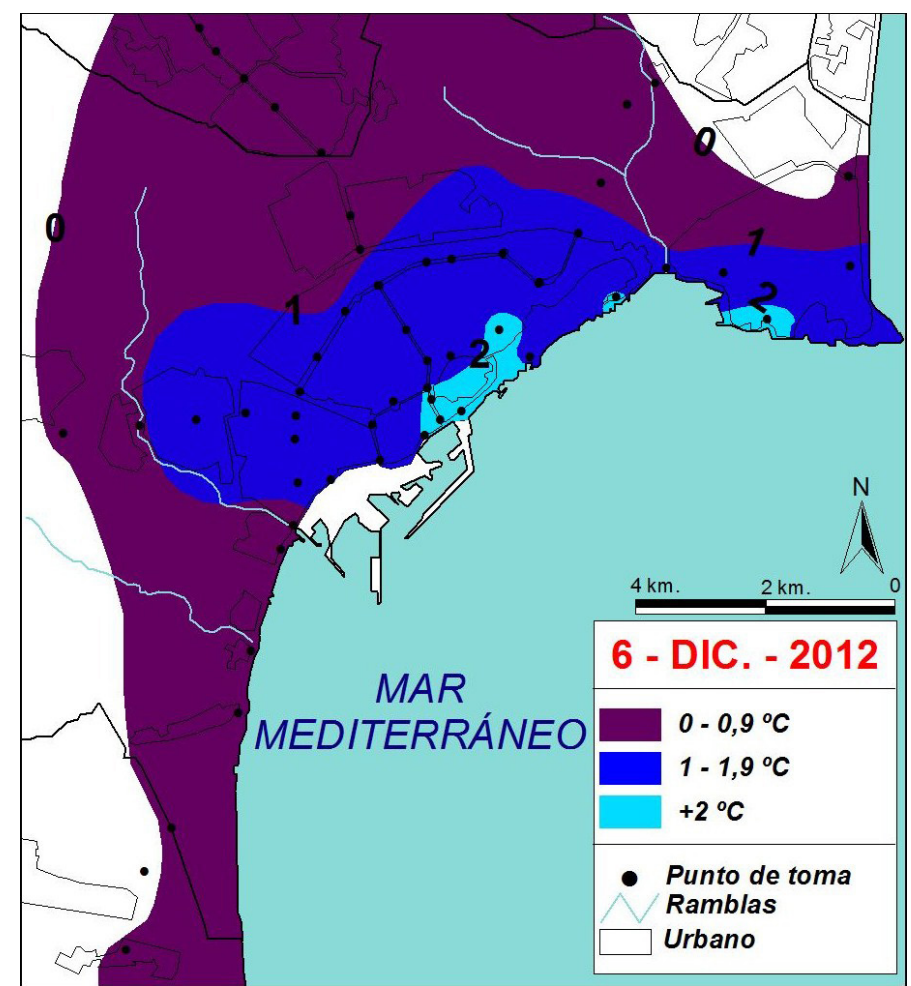


c) Isla de calor desplazada

La configuración que en este tipo de isla de calor adoptan las isotermas podríamos definirla como un caso regional o local, en el que se puede asegurar que sólo se produce en la ciudad de Alicante. Se nos presenta una isla de calor en el que el máximo de intensidad sigue dándose en el mismo ámbito que se ha dado en otras tipologías, pero con la salvedad de que en ámbitos del Oeste de la ciudad, áreas industriales prácticamente despobladas han registrado en torno a los $5-6^{\circ} \mathrm{C}$ de diferencia con la mínima. Podemos hablar entonces de un aire cálido que se ha conectado por varios motivos desde este sector, más frío en otros días, hacia el centro.

Para explicar esta situación de microclima entran en juego el factor meteorológico y el geográfico. El primer factor se explica por las situaciones sinópticas de estos, primero el 27 de Diciembre con una situación anticiclónica en el centro peninsular, pero con una borrasca ubicada en el Mar Cantábrico que atraía vientos del Norte-Noroeste al Sureste peninsular. En cambio, el día 6 de Febrero, el campo de altas presiones se situaba en el Atlántico pero a su vez, en el centro del continente europeo se posicionaba un fuerte sistema de bajas presiones. La situación geográfica de margen de ambos campos isobáricos del área mediterránea peninsular hacía que los vientos de dirección Norte en mayor medida, fuesen de gran velocidad, superándose en Alicante, tanto el día 6 como el 7 de Febrero los 80 km/h.

La parte geográfica que explica la singular formación de esta isla de calor es la posición trasversal a vientos del Noroeste y Norte de una cadena montañosa en las cercanías de la ciudad de Alicante. Estamos hablando de la Serra Fontcalent, que con sus 446 metros, se ofrece como un murallón de disposición Suroeste o Noreste. Este murallón ejerce un efecto muy conocido en Meteorología como es el Efecto Foehn que se explica como un flujo que en contacto con una extensión orográfica asciende por la vertiente a barlovento, enfriándose y pudiendo originar nubes y precipitaciones, con lo cual una porción de su carga higrométrica queda en la vertiente a barlovento, mientras que, desde la vertiente a sotavento la formación nubosa originada parece cortada a pico, bruscamente, es el llamado muro de Foehn. El descenso por la vertiente a sotavento se hace con el gradiente de la adiabática seca, en consecuencia ese viento, ahora catabático, registra mayor temperatura y posee menor humedad relativa.

Así pues, todos los sectores del área de estudio ubicados a sotavento de esta sierra conocen ese calentamiento debido a ese viento fuerte y por ello el origen de denominar a esta isla de calor de desplazada. La configuración de esta isla de calor es la siguiente:

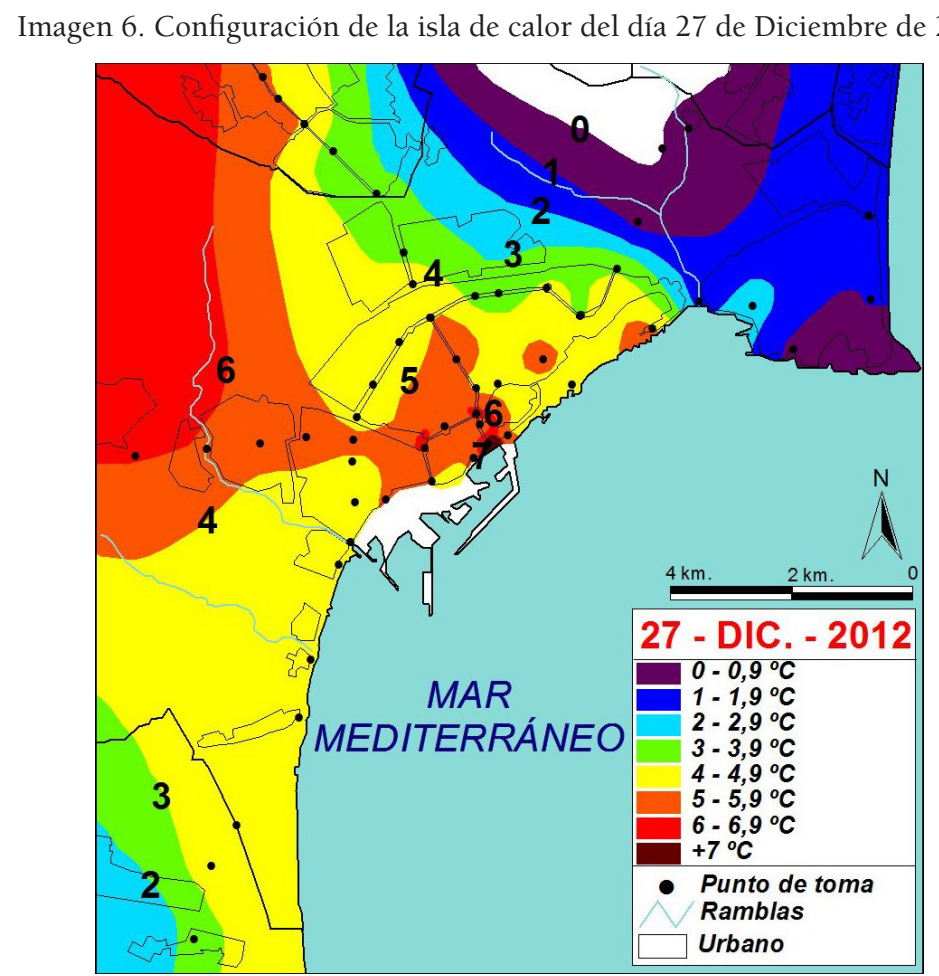

Este día se alcanzó el máximo de intensidad de la isla de calor, con $7^{\circ} \mathrm{C}$ entre la Rambla de Méndez Núñez y la Avenida de Denia a la altura del negocio de Caravanas Ferrero. Este hecho también venía impulsado por la situación anticiclónica que hemos comentado anteriormente que se alargaba varios 
días, amén de que como se observa el aire cálido y seco se canaliza por la Avenida de Orihuela y las vías del ferrocarril y desaguando en el centro urbano. Se aprecia que la salida de la Autovía a Madrid, último punto del transecto centro alcanzó dicho día una diferencia de $6,1^{\circ} \mathrm{C}$, sorprendiendo puesto que es un área prácticamente despoblada. Podemos señalar además que el Este del área de estudio, que queda fuera de la influencia del Efecto Foehn es claramente más frío.

Que la distribución de la isla de calor de Alicante queda modificada por los parámetros aducidos se demuestra perfectamente si comparamos los dos puntos a priori más fríos de todos en los que se han tomado temperaturas. Estamos hablando del punto 2 del transecto centro, Caravanas Ferrero y el punto 16 del litoral, la N-332, los cuales presentan la diferencia media más baja, 0,8 y $1,3^{\circ} \mathrm{C}$ respectivamente, amén de haber sido los puntos más fríos 3 días cada uno. Podemos observar en la gráfica como la nacional, que queda dentro de la influencia del viento Foehn rectifica su normal funcionamiento dentro del fenómeno que estamos demostrando. Esto evidentemente, tendrá su repercusión a la hora de hablar de la morfología media de la isla de calor de Alicante:

Gráfico 3. Diferencia del punto 2 del transecto centro y punto 16 del litoral con respecto al mínimo diario.

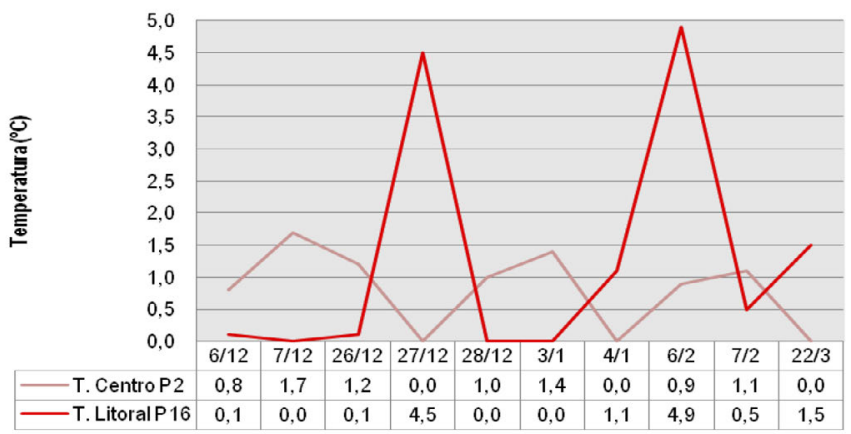

Puede apreciarse que cuando uno registra una gran diferencia respecto al mínimo el otro se presenta precisamente como ese mínimo diario o es uno de los mínimos.

\section{CONCLUSIONES}

Con todo ello, estamos en disposición de presentar el núcleo de este trabajo de investigación, es decir, cuál es la distribución y forma de la isla de calor de la ciudad de Alicante y dónde se sitúa su punto de máxima intensidad. La isla de calor de Alicante se distribuye de la siguiente manera:

Imagen 7. Isla de calor media de la ciudad de Alicante.

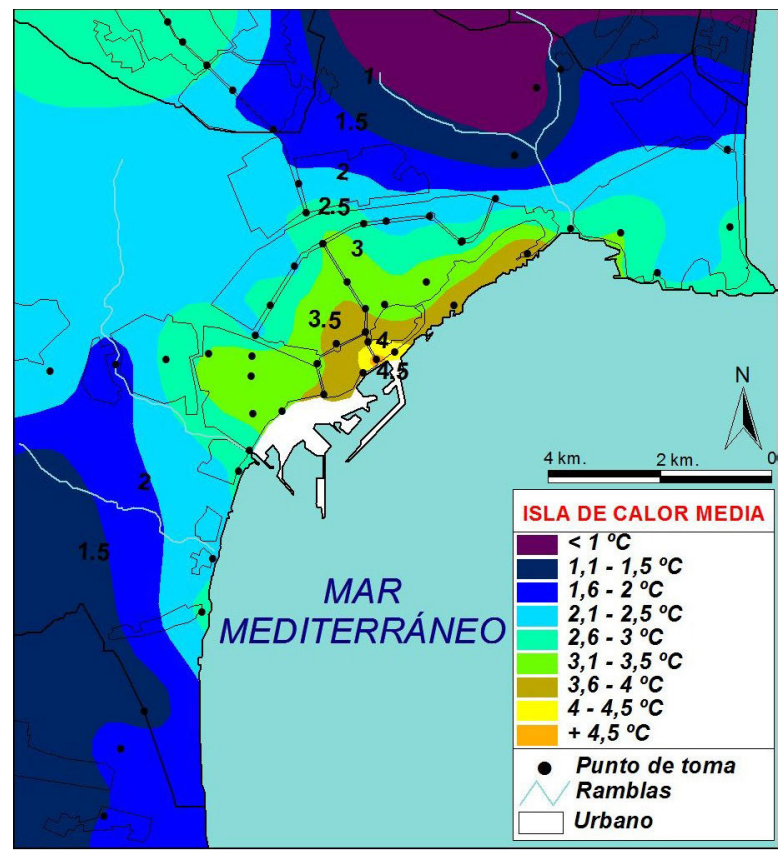


Tenemos por tanto, una isla de calor que se manifiesta en una serie de características:

1) El centro de máxima intensidad se da siempre en el mismo punto o área, con alguna variación diaria, independientemente de la morfología que adquiera el fenómeno de isla de calor. Esta área de máxima intensidad se da en la Rambla de Méndez Núñez en su contacto con la Explanada de España, que llega a una diferencia media de $4,5^{\circ}$, que constituye un punto rodeado por una densidad urbanística compacta y de circulación de vehículos y personas importante. Este punto queda flanqueado por todos sus puntos cardinales por un área de también gran intensidad, como son la Playa de El Postiguet, la Oficina de Turismo y el inicio de la Avenida Óscar Esplá, en la entrada al puerto industrial. Al sur de este centro de máxima intensidad se ubica el mar, pero la concentración del tráfico rodado que circula por la ronda litoral (Avenida Conde de Vallellano y la Avenida de Loring) y el murallón que representan tanto Explanada como Paseo de Canalejas impiden que la influencia marítima atenúe el fenómeno de isla de calor.

2) A partir de este centro de máxima intensidad, la isla de calor alicantina va descendiendo paulatinamente hacia las afueras de la urbe, siendo más intensa en aquellos sectores que pertenecen al centro urbano, de trama urbana densa y que por tanto, están más transitado, como el nodo Alfonso el Sabio-Avenida de la Estación, que se mueve alrededor de los $4^{\circ} \mathrm{C}$. Las zonas más periféricas de la aglomeración urbana son más frías, aún a pesar de ser nodos de fuerte tráfico rodado, puesto que se presentan como espacios más abiertos, tanto urbana como edificatoriamente, como es el caso de la Gran Vía y Vía Parque.

3) Los ríos-rambla que flanquean Alicante por el Suroeste y Noreste, apenas tiene importancia en la morfología media del fenómeno y en días de episodio fuerte o débil. Sólo el Barranco de las Ovejas con vientos del Noroeste intensos que provocan Efecto Foehn hacia la ciudad, es capaz de crear un canal de aire cálido que modifica la distribución de la intensidad del fenómeno.

4) Municipios limítrofes a la capital, como San Vicente del Raspeig, presentan su propia isla de calor, con un sector central en torno a los $2,5^{\circ} \mathrm{C}$ más sobre el mínimo diario. La pedanía de El Altet en cambio, presenta una isla de calor media apenas reseñable, fuertemente influida por los días de isla de calor desplazada.

5) Observando el mapa de isla de calor media de Alicante se concluye que la zona al Suroeste de la ciudad, donde se ubica el Aeropuerto de El Altet, es sensiblemente más cálida que el Noreste de la ciudad, alrededores de la pedanía de Santa Faz, donde se ubica el punto más frío. Esta diferencia radica básicamente en la ubicación de la Serra de Fontcalent situada en el sector occidental y el Efecto Foehn que es capaz de crear, induciendo una anomalía térmica cálida en esta zona.

6) Hay que dejar claro que esta isla de calor es la que ha resultado teniendo en cuenta los distintos transectos a lo largo de toda la ciudad de Alicante. En la realidad, esta isla de calor puede verse modificada puesto que hay áreas de la ciudad en los que ha resultado muy difícil medir la temperatura bien por problemas de tráfico como el Barrio de la Cruz o por problemas de accesibilidad como el Monte del Benacantil o Serra Grossa, que han quedado integrados en las bandas de isotermas.

\section{BIBLIOGRAFÍA}

GIL OlCiNA, A. (dir.) (1990): Historia de la provincia de Alicante. Geografía tomo 1, volúmenes 1 y 2. Ediciones Mediterráneo. Murcia.

GIL OLCINA, A. (dir.) (2001): Cartografía temática de las tierras alicantinas. Edita Instituto Universitario de Geografía, Universidad de Alicante. Alicante, 119 pp.

GIL OLCINA, A. y OLCINA CANTOS, J. (1999): Climatología básica. Ed. Ariel Geografía. Barcelona, 387 pp. GOZÁlVEZ PÉREZ, V. (Dir) (1990): Comarca de L'Alacantí. Edita Mancomunidad de L'Alacantí. Alicante, $248 \mathrm{pp}$.

MAZÓN MARTíNEZ, T. (1994): La configuración del paisaje urbano en Alicante (1960-1990). Edita Instituto de cultura Juan Gil Albert, Diputación de Alicante. Alicante, 221 pp.

MORENO GARCÍA, M. C. (1993): Estudio del clima urbano de Barcelona: la isla de calor. Ed. Oikos-Tau. Barcelona, $193 \mathrm{pp}$.

MORENO GARCÍA, M. C. (1999): Climatología Urbana. Ed. Universitat de Barcelona. Barcelona, 71 pp. ROSELLÓ VERGER, VICENÇ M. (1995): Geografía del País Valenciano. Ed. Alfons el Magnànim. Valencia, 640 pp. 
SERRA PARDO, J. A. (2007): "Estudio de la isla de calor de la ciudad de Ibiza" en Revista de Investigaciones Geográficas del Instituto Universitario de Alicante, No $44,19 \mathrm{pp}$.

VVAA (1990): Historia de Alicante Tomo 2. Edita Ayuntamiento de Alicante, Patronato para la Conmemoración del Quinto Centenario de la Ciudad de Alicante y Diario Información. Alicante, 839 pp.

VVAA (2008): "La isla de calor en Las Palmas de Gran Canaria: intensidad, distribución y factores condicionantes" en Boletín de la AGE, Nº47, 19 pp. 